\title{
CORRIGENDUM
}

\section{Serotonin tranporter methylation and response to cognitive behaviour therapy in children with anxiety disorders}

S Roberts, KJ Lester, JL Hudson, RM Rapee, C Creswell, PJ Cooper, KJ Thirlwall, JRI Coleman, G Breen, CCY Wong and TC Eley

Translational Psychiatry (2014) 4, e467; doi:10.1038/tp.2014.109; published online 14 October 2014

Correction to: Translational Psychiatry (2014) 4, e444; doi:10.1038/ tp.2014.83; published online 16 September 2014

Following publication, the authors noticed that there was a mistake in the title of their paper. The correct title should be:
Serotonin transporter methylation and response to cognitive behaviour therapy in children with anxiety disorders. 